\title{
A formação da imprensa pentecostal no Brasil: um olhar a partir da Casa Publicadora das Assembleias de Deus (CPAD) - 1930-1970
}

André Dioney FONSECA ${ }^{1}$

Resumo:

Este artigo tem como objetivo analisar a formação da imprensa pentecostal no Brasil a partir da fundação da Casa Publicadora das Assembleias de Deus (CPAD). Fruto de iniciativa pioneira das primeiras lideranças da igreja Assembleia de Deus, que queriam fazer circular um modesto jornal de caráter informativo e doutrinário, em algumas décadas a $\mathrm{CPAD}$, de pequena editora que funcionava de maneira improvisada no fundo de uma congregação, alcançou o posto de maior editora pentecostal do país, responsável pela circulação de importantes periódicos, como o jornal Mensageiro da Paz e as revistas A Seara e Lições Bíblicas, além de milhares de livros, bíblias, hinários e folhetos evangelísticos. Desse modo, neste artigo procuramos demonstrar como se deu esse processo de desenvolvimento, entre as décadas de 1930 e 1970 , considerando que muitos pesquisadores já utilizaram em seus estudos sobre a igreja Assembleia de Deus os impressos editados pela CPAD, mas que ainda são poucas as análises históricas de cunho acadêmico focadas estritamente na história dessa editora.

Palavras-chave:

Imprensa pentecostal. Assembleia de Deus. CPAD.

\section{The formation of the Pentecostal press in Brazil: a perspective on the Publishing House of the Assemblies of God (Casa Publicadora das Assembleias de Deus - CPAD) - 1930-1970}

\begin{abstract}
:
This paper will examine the formation of the Pentecostal press in Brazil, starting from the foundation of the Publishing House of the Assemblies of God (Casa Publicadora das Assembleias de Deus - CPAD). It was a result of a pioneering initiative of the first leaders of the Assembly of God church, who wanted to disseminate a modest newspaper with informational purposes. In some decades the CPAD, which was a small publishing house working in an improvised manner at the back of a congregation, became the biggest Pentecostal publishing house of the country, responsible for the circulation of important periodicals, such as the newspaper Mensageiro da Paz and the magazines A Seara and Lições Bíblicas, as well as thousands of books, bibles, hymnals and evangelistic brochures. Therefore, this article intends to demonstrate how it developed between the decades of 1930 and 1970, taking into consideration the fact that many researchers have already utilized the printed material edited by CPAD in their studies about the Assembly of God church, but there are just a few academic historical analysis focused strictly on the history of this publishing house.
\end{abstract}

Keywords:

Pentecostal press. Assembly of God. CPAD.

\section{La formación de la prensa pentecostal en Brasil: una mirada desde la Casa Publica de las Assembleias de Deus (CPAD) - 1930-1970}

Resumen:

Este artículo tiene como objetivo analizar la formación de la prensa pentecostal en Brasil a partir de la fundación de la Casa Publica de las Asambleas de Dios (CPAD). Fruto de iniciativa pionera de los primeros líderes de la iglesia Asamblea de Dios, que querían hacer circular un modesto periódico de carácter informativo y doctrinal, en algunas décadas la CPAD, de pequeña editora que funcionaba de manera improvisada en el fondo de una congregación, alcanzó el puesto de mayor editorial pentecostal del país, responsable de la circulación de importantes periódicos, como el diario Mensageiro da Paz y las revistas A

\footnotetext{
${ }^{1}$ Doutor em História Social pela Universidade de São Paulo (USP). Professor Adjunto do Curso de História da Universidade Federal do Oeste do Pará (UFOPA) e do Programa de Pós-Graduação em Educação (PPGE/UFOPA). E-mail: andredioney@yahoo.com.br
} 
Seara y Lições Bíblicas, además de miles de libros, biblias, himnos y folletos evangelísticos. De este modo, en este artículo procuramos demostrar cómo se dio ese proceso de desarrollo, entre las décadas de 1930 y 1970, considerando que muchos investigadores ya utilizaron en sus estudios sobre la iglesia Asamblea de Dios los impresos editados por la CPAD, pero que todavía son pocos los análisis históricos de cuño académico enfocados estrictamente en la historia de esa editorial.

Palabras clave:

Prensa pentecostal. Asamblea de Dios. CPAD.

\section{Introdução}

É difícil encontrarmos um estudo sobre a história da igreja Assembleia de Deus (doravante $\mathrm{AD}$ ) que não tenha recorrido aos periódicos publicados por essa instituição ao longo de sua centenária presença em nosso país. A socióloga Beatriz Muniz de Souza (1969), em suas pioneiras pesquisas sobre o movimento pentecostal no Brasil, por exemplo, utilizou o jornal Mensageiro da Paz e a revista Lições Bíblicas em busca de informações que não estavam registradas em nenhum outro documento oficial da igreja. $\mathrm{O}$ mesmo pode ser dito dos trabalhos de Francisco Cartaxo Rolim (1987; 1994) e Paul Freston (1994), sociólogos que, em seus estudos sobre o movimento pentecostal no Brasil, ao analisarem a $\mathrm{AD}$, buscaram apoio nos jornais e revistas editados pela Casa Publicadora das Assembleias de Deus (CPAD), a editora oficial assembleiana.

A partir da década de 1990, com o rápido desenvolvimento das pesquisas abrigadas nos programas de pós-graduação, assistimos a um aumento significativo de estudos sobre a $\mathrm{AD}$ espalhados pelas diferentes áreas do saber, especialmente no campo da história, da sociologia e das ciências da religião. Não seria o caso de listá-los todos no escopo deste texto, basta apenas registrar que são raras as listagens de fontes dessas teses e dissertações em que não encontramos arrolados os periódicos publicados pela CPAD.

Não é difícil entender essa lógica, em se tratando de uma igreja com as características da $\mathrm{AD}$, que não desenvolveu, ao longo de seu processo de institucionalização, um corpo burocrático centralizado capaz de fazer circular ofícios, circulares, memorandos, resoluções etc. de maneira minimamente organizada e que garantisse o efetivo alcance de todos os templos espalhados pelo país. É por isso que, por muitos anos, as decisões tomadas pela Convenção Geral das Assembleias de Deus no Brasil (CGADB) eram levadas ao conhecimento dos membros e das lideranças por meio dos periódicos, sobretudo o jornal Mensageiro da Paz.

Em razão disso, além dos jornais, revistas e livros oficiais publicados pela CPAD, um pesquisador interessado em analisar a $\mathrm{AD}$ encontrará pouca fonte impressa ${ }^{2}$ disponível.

\footnotetext{
${ }^{2}$ Estamos nos referindo a documentos como atas, memorandos, circulares, correspondências, por exemplo.
} 
É verdade que diferentes instrumentais metodológicos que permitem a realização de entrevistas têm sido amplamente utilizados nas últimas décadas, mas é igualmente certo que esse recurso, dependendo da problemática levantada pelo pesquisador e do recorte cronológico escolhido, mostra-se limitado. Essas circunstâncias explicam a importância das milhares de páginas do jornal Mensageiro da Paz e das revistas publicadas pela $\mathrm{CPAD}^{3}$, pois, sem elas, elementos basilares da história dessa igreja, no decurso de um século de atividade em nosso país, não estariam à disposição dos estudiosos.

Atualmente, os historiadores da imprensa têm criticado os estudos históricos que se lançam à consulta de periódicos sem considerar o lugar social em que foram produzidos e as técnicas envolvidas em sua impressão (LUCA, 2006). Desse modo, nosso objetivo é apresentar alguns apontamentos históricos da formação da imprensa pentecostal no Brasil, tomando como foco a CPAD. Não temos a intenção, evidentemente, de explorar a história dessa editora de forma detalhada, considerando os limites deste texto, mas de apresentar um painel histórico que poderá servir como ponto de partida para futuros estudiosos que vierem a pesquisar os periódicos publicados pela editora assembleiana.

\section{Casa Publicadora das Assembleias de Deus (CPAD)}

Desde os primeiros anos de fundação da $\mathrm{AD}$, os pioneiros reconheciam a importância da imprensa para a propagação de suas mensagens (OLIVEIRA, 1997; ALMEIDA, 1982). Essa inclinação ao periodismo, contudo, exigiu grande esforço da liderança da $\mathrm{AD}$, pois, como se sabe, a manutenção de uma publicação periódica na segunda metade do século XX era sempre uma tarefa muito desafiadora, especialmente pelos custos envolvidos na produção de impressos (ELEUTÉRIO, 2008).

Até o ano 1948, os periódicos da AD eram impressos em gráficas particulares. Uma editora própria, com os elementos mínimos que a tornassem digna desse nome, era algo muito distante das possibilidades da $\mathrm{AD}$ das primeiras décadas do século XX. A redação do jornal Mensageiro da Paz, na qual também eram revisadas as revistas Lições Bíblicas, funcionava de forma itinerante, ora na casa de alguns pastores, ora anexa às instalações da AD de São Cristóvão, na cidade do Rio de Janeiro (BREVE..., 1970, p. 11).

Os custos envolvidos na organização de uma editora, com um corpo fixo de funcionários e maquinário gráfico, impediam que a igreja fosse além das improvisadas e itinerantes instalações. O próprio nome, Casa Publicadora, que fora aprovado na

\footnotetext{
${ }^{3}$ Lições Bíblicas, A Seara, O Obreiro, Jovem Cristão e Círculo de Oração.
} 
Convenção Geral das Assembleias de Deus, realizada em Belém, no Pará, em 1936, não sinalizava a criação de um parque gráfico próprio para a $\mathrm{AD}$, apenas servia para denominar a união das diversas caixas que reuniam recursos destinados à área de publicação (CPAD, 2004, p. $\left.116-117^{4}\right)$.

O caixa central da $\mathrm{CPAD}$, ao que indicam os registros, operava sempre no vermelho nesse período, pois, mesmo com uma crescente demanda por impressos, o valor arrecadado com a comercialização não era o bastante para cobrir sequer os custos de produção. Por isso, a redação dependia de doações das igrejas espalhadas pelo país e ainda contava com ofertas internacionais para se manter (CPAD, 2004). ${ }^{5}$ A partir da década de 1940, no entanto, as peças do tabuleiro da história moveram-se, alterando completamente o cenário. O que antes parecia algo distante em pouco tempo passou a ser não só um objetivo possível, mas um intento de máxima necessidade.

Inicialmente, devemos destacar que, nos anos 1940, a AD passou a contar com a presença de missionários americanos, muito insignificantes em número, é verdade, mas bem representativos quando o assunto eram recursos financeiros. E serão exatamente os dólares aviados por esses missionários que ajudarão sobremaneira o caixa destinado à criação da CPAD. O segundo dado importante é que os líderes da $\mathrm{AD}$ tiveram de transformar sua Casa Publicadora em pessoa jurídica para atender a um decreto governamental. Tratava-se da política coordenada pelo Departamento de Imprensa e Propaganda (DIP), que obrigava todas as entidades mantenedoras de impressos a registrálos no recém-criado departamento, sob a ameaça de impedir a circulação daqueles que não se enquadrassem nas recomendações do Estado Novo (BELOCH; ABREU, 2001, p. 10761079).

Foi para atender a essa imposição do Estado e com o incentivo dos dólares dos missionários norte-americanos que a liderança da $\mathrm{AD}$, mesmo sem a imediata intenção de montar um parque gráfico, oficializou o registro da editora no 3ํㅡㅁ Ofício de Registro de Títulos e Documentos do Rio de Janeiro, no livro K, número 01, com o nome de Casa Publicadora da Assembleia de Deus (CPAD), que passou a ser propriedade imediata do jornal Mensageiro da Paz (RIO DE JANEIRO, 1947).

Até meados da década de 1940, apesar de ter como principal missão atender às igrejas, a CPAD não pertencia a nenhuma delas, nem mesmo à Convenção Geral das

\footnotetext{
${ }^{4}$ Embora não haja citação direta, a indicação da página será mantida para localização precisa da informação. O mesmo procedimento será usado em outras referências ao longo do texto.

${ }^{5}$ Discurso de Samuel Nyströn (CPAD, 2004, p. 117).
} 
Assembleias de Deus (CGADB). Suas dependências se resumiam a seis pequenas salas nos fundos da $\mathrm{AD}$ de São Cristóvão, no Rio de Janeiro. Juntas, as salas que serviam como redação, secretaria, tesouraria, depósito e expedição perfaziam um total de $160 \mathrm{~m}^{2}$ (ARAUJO, 2007, p. 167).

Em 1946, novamente a liderança da AD seria forçada a repensar o futuro da CPAD, dessa vez sob pressões internas e externas. A pressão externa ocorreu por uma séria crise financeira pela qual passava a empresa que prestava serviço de impressão dos materiais que eram distribuídos pela CPAD. No âmbito interno, pesou a decisão da CGADB de tornar-se pessoa jurídica. Nessa nova configuração, o estatuto da $\mathrm{CPAD}$, escrito às pressas quando da publicação da lei de imprensa do Estado Novo, teve de ser reformulado para que, a partir de então, a CPAD passasse a ser propriedade exclusiva da CGADB (ARAUJO, 2007).

Diante desse novo quadro em que se encontrava a editora, os pastores reunidos na Convenção Geral das Assembleias de Deus, realizada em Recife, em 1946, discutiram pela primeira vez a possibilidade de construção de instalações próprias para as atividades administrativas da CPAD e de um parque gráfico próprio. Mas essa operação dependia de grande investimento financeiro, e a CPAD, cuja existência dependia do subsídio das igrejas, não tinha recursos próprios para tal empreendimento. Os valores envolvidos na compra de um terreno, construção das instalações e compra de maquinário dividiram a opinião dos convencionais, e os debates ficaram acirrados (CPAD, 2004, p. 226). ${ }^{6}$

Emílio Conde, funcionário da casa editorial e principal entusiasta da proposta que estava em apreciação, apresentou um relatório com resultados da CPAD com o intuito de reforçar a "importância" e a "eficácia" da editora. Após os dados esboçados pelo relatório de Emílio Conde, a criação das novas dependências para a CPAD foi aprovada. Confirmada a vitória, os pastores apressaram-se em lançar um programa denominado Campanha do Milhão, alusivo à meta de arrecadação de 1 milhão de cruzeiros ${ }^{7}$, que seria destinado à compra de uma máquina tipográfica (CPAD, 2004, p. 226).

\footnotetext{
${ }^{6}$ Convenção Geral de 1946. Sessão do dia 25 de outubro (CPAD, 2004, p. 226).

${ }^{7}$ Para se ter uma ideia da grandeza desse montante, nesse período, o salário mínimo seguia o valor do Decreto no 5.977, de 10 de novembro de 1943, que era de Cr\$ 380,00. Deve-se acrescentar ainda que, em 1945, em razão da queda de Getúlio Vargas, o programa do salário mínimo, que previa um reajuste em 1946, foi descontinuado. Um novo piso foi estabelecido somente em 1951, com o Decreto no 30.342, de 24 de dezembro de 1951, que estipulou o valor do salário mínimo em Cr\$1.200,00. De todo modo, esse parâmetro ajuda a dimensionar o quanto eram vultosas as cifras envolvidas nas discussões sobre a CPAD.
} 
No bojo das mudanças que haviam sido aprovadas pelo plenário da Convenção Geral, a CPAD publicou, no Diário Oficial da União (DOU) do início de 1947, o extrato da reformulação de seus estatutos, por meio do qual apresentava as principais diretrizes da editora:

[A CPAD] Publicará: a) revistas, livros, jornais, folhetos de caráter educativo e Instrutivo e de fundo evangélico; b) incentivará e contribuirá para a criação e manutenção de orfanatos, asilos para velhos desamparados, institutos educativos; c) angariará os recursos necessários à sua finalidade. A Casa Publicadora da Assembléia de Deus, será administrada por um Conselho Constituído de sete (7) membros eleitos pela Reunião Geral da Convocação das Assembléia de Deus. (CPAD, 1947, p. 2039)

Aspecto que merece destaque nesse extrato dos estatutos levado a conhecimento público por meio do DOU é a existência de um "conselho" cujos membros seriam eleitos pela CGADB. A existência desse coletivo era estratégica em um momento em que se projetava o crescimento da editora, pois garantia que a Convenção Geral, recémconstituída como pessoa jurídica, influenciasse diretamente as atividades da CPAD.

Passado um ano do lançamento oficial da Campanha do Milhão, a Convenção Geral voltou a discutir a instalação da nova CPAD. A proposta, que fora aprovada em 1946, ainda era vista com muitas reservas por uma parcela dos convencionais, principalmente pelos custos que envolviam tal operação. O porta-voz daqueles que ainda não se achavam suficientemente convencidos da viabilidade da mobilização em prol da CPAD foi José Teixeira Rego (CPAD, 2004, p. 239-241). ${ }^{8}$

Para Rego, era preciso esclarecer se a CPAD tinha como função contribuir com as igrejas, provendo-as de "literatura", ou se sua função era meramente "comercial", uma vez que os preços de seus produtos eram "muito altos". Já o missionário Bruno Skolimowski preocupava-se com o destino das ofertas alçadas em favor da editora, indagando se também eram destinadas aos institutos bíblicos. A este, Conde respondeu confirmando a primazia do destino das ofertas às necessidades da editora; àquele, replicou informando que os valores dos produtos estavam de acordo com as "necessidades da editora" e enfatizou que a CPAD tinha, acima de tudo, um “caráter espiritual” (CPAD, 2004, p. 239241).

Após alguns momentos de tensão, os debates convergiram em direção a um único ponto: onde seria instalada a CPAD? A decisão deveria ser tomada com urgência, pois John Peter Kolenda, missionário norte-americano, já havia anunciado a importação das

\footnotetext{
${ }^{8}$ Convenção Geral de 1947. Sessão do dia 8 de outubro (CPAD, 2004, p. 239-241).
} 
máquinas que comporiam a oficina gráfica da $\mathrm{CPAD}$ e lembrou que a compra do maquinário havia sido efetivada por ele mediante um empréstimo de 20 mil dólares feito nos Estados Unidos. A forma de pagamento do crédito revela o engajamento de Kolenda no projeto de estruturação da $\mathrm{CPAD}$, pois ele próprio assumira a metade da dívida e ainda comunicou que os 10 mil dólares restantes poderiam ser pagos pela Convenção Geral até 1951 a juros de $3 \%$ ao ano (CPAD, 2004, p. 239-241).

Mesmo em face da generosa oferta de Kolenda e da módica proposta de pagamento do empréstimo, o dissenso reinava entre os integrantes da Convenção. Havia os que defendiam a conveniência da cidade de São Paulo para sediar a nova editora, enquanto outros acreditavam ser a capital federal, Rio de Janeiro, a melhor opção. O tamanho adequado das futuras instalações também era um pomo de discórdia entre os pastores, pois, ao passo que os entusiastas da nova CPAD propunham um espaço que compreendesse 300 $\mathrm{m}^{2}$, o grupo que sempre viu com reservas o modelo proposto para a nova CPAD afirmava que não deveria haver exagero (CPAD, 2004, p. 239-241). "O senhor Jesus sempre começa com as pequenas coisas" (CPAD, 2004, p. 240), advertiu o renomado pastor Paulo Leivas Macalão.

O clima de discussões com infindáveis propostas, respostas e apartes impossibilitou a votação do tema. Como era costume em tais situações, a CGADB formou uma comissão especial para tratar do assunto. Após alguns meses de ampla negociação, decidiu-se que as instalações da CPAD (mais especificamente um galpão de 5×30 m) seriam construídas na então capital federal do país, à rua Olímpio de Melo, 581 (CPAD, 2004, p. 241). ${ }^{9}$

Os pastores envolvidos no debate tinham sérias preocupações, pois valores envolvidos nas transações eram altíssimos. O terreno foi comprado pelo valor de $\mathrm{Cr} \$$ 1.587.592,50, negociado mediante uma entrada de Cr\$ 984.240,00, que deveria ser seguida por três parcelas semestrais. Além dos Cr\$ 727.086,00 já desembolsados para a importação de uma linotipo, ainda era necessário um investimento de $\mathrm{Cr} \$ 800.000,00$ em máquinas para que a oficina da CPAD pudesse entrar em funcionamento (ARAUJO, 2007, p. 169170).

Na Convenção Geral de 1948, a CPAD voltou a ser debatida pelos pastores reunidos em Natal $(\mathrm{RN})$. Uma vez adquiridos o terreno e as máquinas, restava iniciar as obras de construção do galpão. Contudo, faltavam recursos para manter o projeto inicial, que previa um amplo espaço para as atividades de impressão; por isso, medidas drásticas

\footnotetext{
${ }^{9}$ Convenção Geral de 1947. Sessão do dia 8 de outubro (CPAD, 2004, p. 241).
} 
foram tomadas pela Convenção: redução da área construída e venda de parte do terreno recém-comprado. $\mathrm{O}$ custo final da edificação não poderia ultrapassar 50 mil cruzeiros. A grave situação financeira, ocasionada pelos vultosos investimentos que haviam sido realizados, fez com que a Convenção Geral deliberasse a favor de uma mobilização nacional de arrecadação que abrangesse todas as ADs do Brasil e que deveria ser repetida todo ano no sétimo dia do mês de setembro, data que deveria ser oficialmente reconhecida como "O dia da Casa Publicadora" (CPAD, 2004, p. 259). ${ }^{10}$

Enquanto os impasses sobre as instalações da CPAD movimentavam a liderança assembleiana, as máquinas recém-importadas foram abrigadas na redação do jornal Mensageiro da Paz, que funcionava anexa à AD São Cristóvão (RJ). Em janeiro de 1949, as primeiras impressões nas instalações temporárias foram feitas com o auxílio do técnico norte-americano Andrew Hargrave, que viera ao Brasil com o objetivo de dar orientações para o corpo de funcionários (ARAUJO, 2007, p. 171).

As dificuldades financeiras e os entraves que dificultavam as exportações de máquinas nesse período (CAMARGO, 2003) não intimidavam os coordenadores da editora, que continuavam investindo em novos maquinários, conforme indica o relatório apresentado na Convenção Geral de 1949, na qual Kolenda informava a compra de uma "impressora" e uma "dobradeira", ambas importadas dos Estados Unidos (CPAD, 2004, p. 271). ${ }^{11}$ Em matéria comemorativa dos 50 anos da CPAD, publicada no jornal Mensageiro da Paz, as aquisições efetuadas em 1949 foram descritas da seguinte forma: "uma linotipo, dois prelos e outras pequenas máquinas auxiliares" (CPAD: ..., 1990, p. 14-15).

Mas os reflexos dos altos investimentos não tardaram a se manifestar. Na década de 1950, a CPAD enfrentou sérios problemas financeiros, principalmente por causa dos empréstimos que foram tomados nos anos 1940. Entre a gestão de João Pereira de Andrade e Silva, iniciada em 1952, e a de Túlio Barros Ferreira, que se estendeu de 1958 a 1960, a editora concentrou forças para quitar suas dívidas, sobretudo o empréstimo de 10 mil dólares tomado por Kolenda, cuja forma de pagamento (que, inicialmente, mostrou-se bastante cômoda) tornou-se embaraçosa pela desvalorização da moeda brasileira (EDITORIAL..., 1970, p. 02; ENTREVISTA..., 1970, p. 19).

Na CGADB, realizada em 1951, na cidade de Porto Alegre (RS), os relatórios apresentados aos participantes da Convenção davam ciência de que o jornal Mensageiro da

\footnotetext{
10 Convenção Geral de 1948. Sessão do dia 26 de novembro (CPAD, 2004, p. 259).

11 Convenção Geral de 1949. Sessão do dia 11 de novembro (CPAD, 2004, p. 271).
} 
Paz trabalhava com deficit de 9 mil cruzeiros mensais (CPAD, 2004, p. 282). ${ }^{12}$ Os coordenadores da casa queriam, mediante os dados, convencer os pastores da necessidade de reajuste no preço do referido jornal. É interessante destacar que os diretores da CPAD não tinham autorização para reajustar o preço de seus produtos sem antes consultar a CGADB, o que dificultava sobremaneira sua organização financeira. As palavras de Emílio Conde na CGADB de Porto Alegre revelam que essa submissão levava a CPAD a um modelo comercial totalmente inviável, pois, segundo ele, entre 1945 e 1951, mesmo que a inflação acumulada passasse de $600 \%$, o preço do jornal não havia sofrido nenhum reajuste (CPAD, 2004, p. 283).

Para os diretores da CPAD, a situação era considerada insustentável. Ou os pastores liberavam a CPAD para decidir os preços de acordo com suas necessidades, ou arcavam com os débitos ocasionados pelos preços defasados. Acabou prevalecendo a opção pelo aumento dos preços ficando a cargo da direção da editora, o que representou um grande avanço em termos administrativos para a CPAD. Gozando de maior autonomia, a CPAD, mesmo com parte de seus lucros comprometidos com empréstimos internacionais, iniciou, a partir de 1952, sob a gerência do pastor João Pereira de Andrade e Silva, uma trajetória de amplo desenvolvimento, como será visto a seguir.

No ano 1950, foram adquiridas uma impressora, duas máquinas auxiliares e uma dobradeira da marca Cleveland Ohio, com capacidade para dobrar 1.500 páginas por hora, e em 1952 e em 1957 novas máquinas foram compradas, entre elas uma impressora automática Rex, que custou à CPAD 800 mil cruzeiros (CPAD:..., 1990, p. 14-15). ${ }^{13} \mathrm{~A}$ aquisição desse maquinário foi uma ação temerária, se considerarmos as dificuldades financeiras que a CPAD enfrentava nesse período e os custos envolvidos nessas aquisições.

Mesmo com tantas dificuldades, a verdade é que a editora acumulou importantes avanços no decorrer da década de 1950, e, por causa do aumento de demanda por impressos, no início dos anos 1960, durante a Convenção Geral, realizada em Recife, Pernambuco, em 1962, um novo programa de modernização da casa editorial assembleiana foi apresentado à CGADB (POR QUE..., 1963). Novamente, as instalações estavam no centro das reclamações do gerente da CPAD, Deolando de Almeida (substituto de Andrade e Silva), que pediu aos convencionais que fosse aprovada uma campanha nacional em prol

12 Convenção Geral de 1951. Sessão do dia 24 de outubro (CPAD, 2004, p. 282).

13 Os valores do salário mínimo, nos anos 1950, foram os seguintes: entre 1951 e 1954, Cr\$ 1.200,00 (Decreto no 30.342, de 24 de dezembro de 1951); entre 1956 e 1958, Cr\$ 3.800,00 (Decreto no 39.604-A, de 14 de julho de 1956); entre 1958 e 1960, Cr\$ 6.000,00 (Decreto no 45.106-A, de 24 de dezembro de 1958). 
da construção de um novo prédio para a CPAD (POR QUE..., 1963). Almeida foi duro em sua explanação, defendendo a proposta com os seguintes argumentos:

Considerando que as atuais instalações funcionam em caráter provisório desde que a Casa foi fundada; considerando que essas instalações estão na iminência de desabar (...), considerando que a velha casa que havia no terreno, e que foi adaptada, já era construção antiga e obsoleta quando se instalou a Casa; considerando que o pensamento dos fundadores da Casa foi o da construção de um prédio melhor, tão logo fôsse possível; considerando que as atuais instalações mesmo que passem a continuar a servir, não mais oferecem condições de trabalho para os empregados, devido ao pouco espaço existente; pois o vacilante casarão é pequeno demais para acomodar a quantos ali labutam (...), considerando que $o$ Brasil pentecostal está exigindo uma produção três ou quatro vêzes maior à atual (...) considerando que a Casa no momento, é um velho pardieiro, mal distribuído, que não recomenda o bom nome das Assembléias de Deus no Brasil, decepcionando nossos visitantes do país e do exterior, e isso não tem razão de ser [...] (POR QUE..., 1963, p. 8, grifos do original). ${ }^{14}$

Os reclamos de Deolando, em seu discurso na tribuna da CGADB, revelam o nível de improviso com que operava a CPAD no início dos anos 1960. Da descrição pode-se perceber que as instalações estavam em uma situação tal de precariedade que havia o receio de o "casarão" desabar sobre os funcionários, que se comprimiam no diminuto espaço de que dispunham para desenvolver suas atividades. A demanda por impressos era crescente, mas o "velho pardieiro", que, segundo Deolando, fazia vergonha ao nome da igreja, operava no limite e sob a ameaça de um colapso, senão de uma tragédia.

Os convencionais, ao que apontam os registros da CGADB, sensibilizaram-se com a gravidade da situação e aprovaram a proposta de mobilização para arrecadar recursos financeiros. Já na edição de janeiro/fevereiro de 1963, a revista A Seara trouxe um anúncio intitulado "Campanha pró-construção da Casa Publicadora” (CAMPANHA..., 1963, p. 12). Em novembro de 1963, A Seara dedicou uma reportagem especial à CPAD, tendo como ilustração de capa o desenho do projeto do novo prédio (Figura 1), que era acompanhado da seguinte frase: "Eis a Casa Publicadora do Futuro! Não demorará muito, e as Assembléias de Deus estarão inaugurando suas instalações, pois esta obra é de fé" (EIS..., 1963, p. 1). A imagem do projeto, destacada na capa da edição, mostrava um conjunto arrojado de edificações, com dois blocos longilíneos unidos por uma estrutura elevada de formas arredondadas em cujo frontispício podia-se ver, em destaque, o nome da editora.

\footnotetext{
${ }^{14}$ Discurso de Deolando Almeida na CGADB de 1962. (POR QUE...1963, p. 8.)
} 
Figura 1 - Ilustração do novo prédio da CPAD (1963).

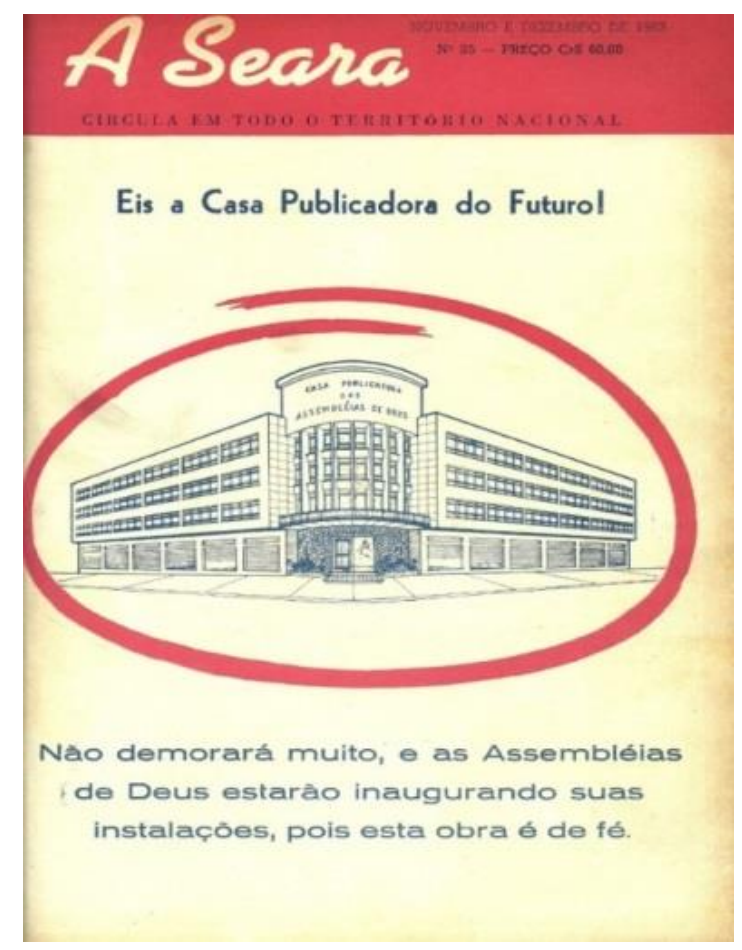

Fonte: A Seara, Rio de Janeiro, n. 35, p. 1, nov./dez. 1963.

No interior da revista, a reportagem "O que é a Casa Publicadora" apresentou aos leitores uma ligeira descrição do funcionamento da editora assembleiana desde 1947 e sem meias palavras deu vazão ao assunto principal: a situação de precariedade em que operava a CPAD, tal como já havia sido esboçado no discurso de Deolando Almeida, na CGADB de 1962. A diferença estava no fato de que, nas páginas de A Seara, esse tipo de informação deixava o restrito ambiente do plenário da CGADB para alcançar o grande público, uma opção ousada por escancarar uma face da editora que poucos leitores conheciam, mas perfeitamente congruente com a mobilização de socorro à CPAD que estava em articulação. A chamada de abertura da reportagem não deixava dúvidas a esse respeito:

A maioria dos irmãos em todo Brasil desconhece o que é a Casa Publicadora. Muitos acreditaram ser um edifício imponente, amplo, de linhas majestosas, bem equipado. Acontece, porém, que é muito o contrário disso. Nesta reportagem desejamos retratar a Casa Publicadora com suas precárias instalações, seu equipamento escasso, seus funcionários em número reduzido [...] (O QUE..., 1963, p. 5).

As reclamações assumiram um tom especial de dramaticidade no interior do texto, indicando, inclusive, que as péssimas condições estruturais do prédio da CPAD colocavam 
em risco todos os trabalhadores da casa editorial, uma vez que o risco de desabamento ou de incêndio era iminente:

O prédio onde funciona [a $\mathrm{CPAD}]$ é a velha casa [...] um casarão tão antigo que pode ruir a qualquer momento [...] isto sem contar na possibilidade de um catastrófico incêndio [...] ao lado esquerdo ao fundo do terreno erguem-se os galpões das Oficinas, estreitos e compridos, agarrados às paredes das casas vizinhas, mal cabendo as poucas máquinas que temos e os operários que ali se comprimem [...] imaginem os leitores que a produção da Casa exige pelo menos o dôbro em equipamento maquinizado! Êsse conjunto, visto de fora, e que fica abaixo do nível da rua permitindo a época de chuvas, às vezes devastadoras enchentes, mas parece um amontoado inexpressivo e deserto. Ninguém dirá que ali está sediada a Casa Publicadora das Assembléias de Deus no Brasil! (O QUE..., 1963, p. 5, grifo nosso).

De acordo com a reportagem, a CPAD tinha sete setores principais: conselho administrativo, gerência, redação, escritório, serviços diversos, oficinas e expedição. Uma ilustração mostrava ao leitor como os setores eram distribuídos (Figura 2). Uma análise mais detalhada do croqui revela que não havia exagero nos relatos que apontavam para o total improviso em que se achava o ambiente de serviço da editora, uma vez que, conforme indica o desenho, um pequeno galpão abrigava os sete setores, que eram subdivididos em 28 seções, nas quais laboravam 88 funcionários.

Figura 2 - Gráfico dos setores da CPAD.

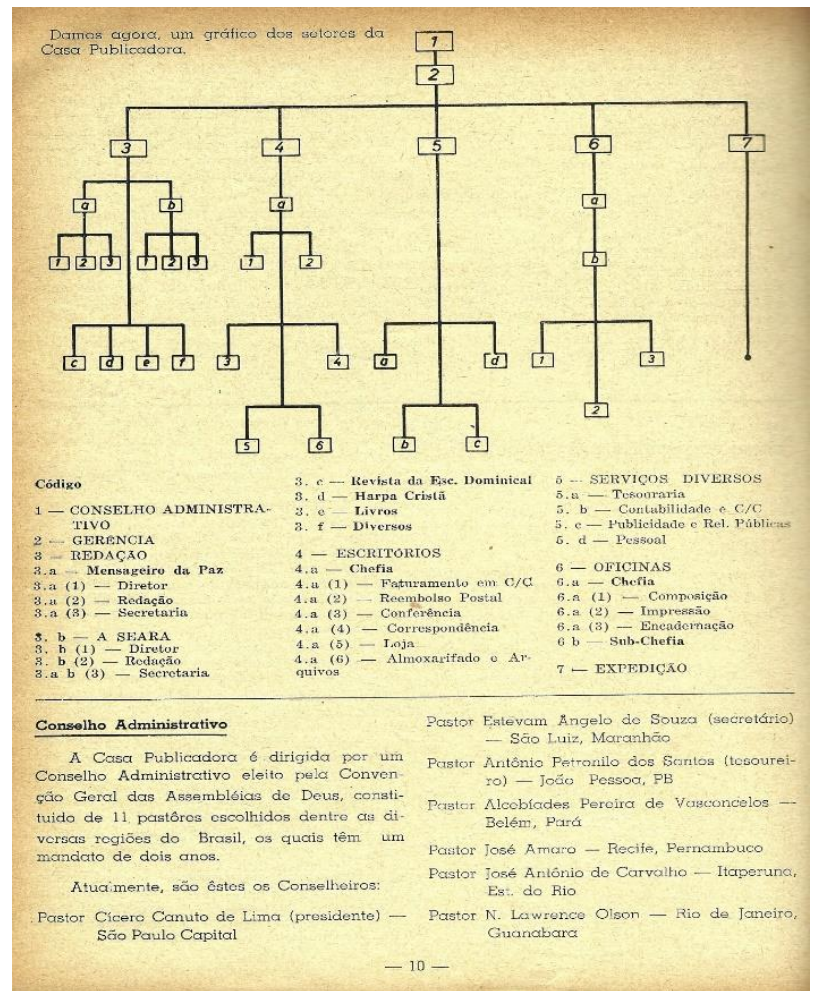

Fonte: A Seara, Rio de Janeiro, n. 35, p. 10, nov./dez. 1963. 
Sobre as oficinas pesavam as maiores reclamações. No setor de composição, segundo informação da reportagem, havia duas máquinas de linotipo, que eram insuficientes à demanda da editora, operadas por dois funcionários responsáveis pela divisão de paginação, preparando as chapas dos espelhos que compunham as páginas destinadas à impressão. Na seção de impressão, o serviço era executado por sete máquinas, além de uma máquina de dobrar os periódicos e uma máquina de corte, todas aquém das necessidades, por serem “antiquadas” e "obsoletas” (O QUE..., 1963, p. 19).

No afã de sensibilizar os leitores, a revista publicou ainda algumas fotos, acompanhadas de legendas, que reforçavam a situação de precariedade da gráfica da CPAD (Figura 3). Com a legenda "equipe especializada em encadernação a couro [...] comprimidos no pequeno sótão que o Gerente mandou construir", na primeira foto podiam-se ver alguns funcionários em um estreito corredor atulhado de caixas e maquinários. Nas duas fotos seguintes, dava-se uma visão panorâmica da oficina, ainda com as legendas em tom reivindicatório: "visão geral da seção de impressão. Maquinário, operários, e material quasi [sic] um por cima dos outros" (O QUE..., 1963, p. 19).

Figura 3 - Fotografias das dependências da CPAD.

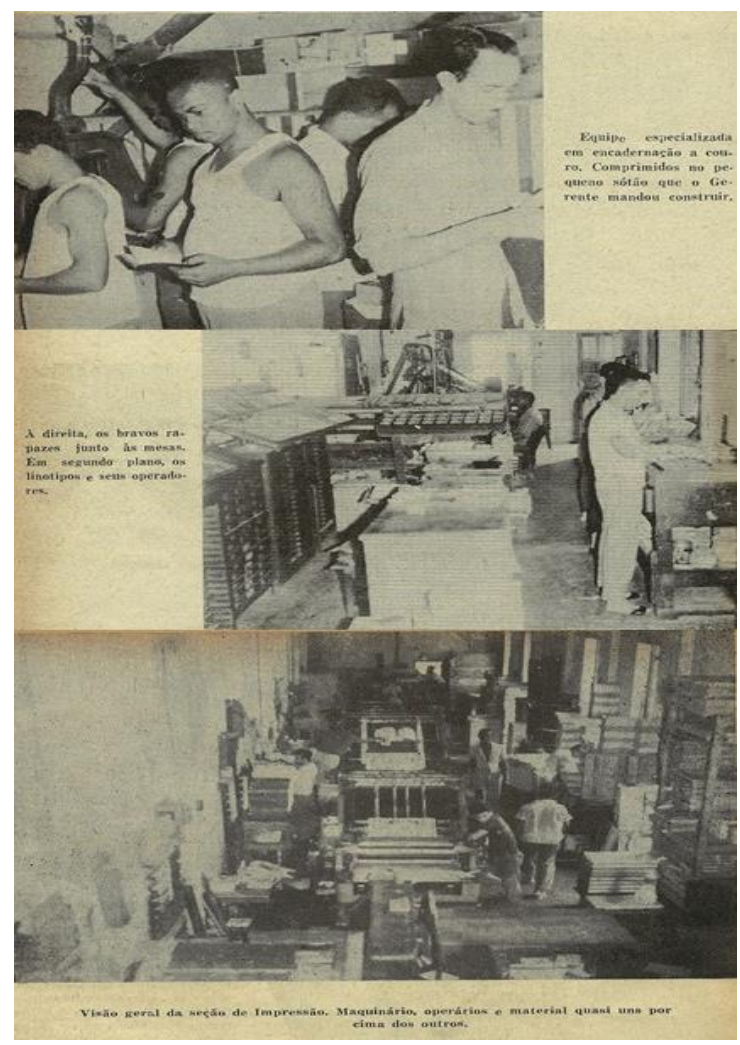

Fonte: A Seara, Rio de Janeiro, n. 35, p. 16-17, nov./dez. 1963. 
O somatório desses problemas afetava sobremaneira as atividades nas oficinas de impressão, pois, com a grave limitação de espaço, era impossível contratar mais funcionários e abrigar novos maquinários. Essa situação fazia do processo de impressão de uma única série do jornal Mensageiro da Paz uma atividade que poderia levar até 32 dias, ao passo que uma edição da revista Lições Bíblicas (utilizadas nas escolas dominicais) poderia tomar até quatro meses de trabalho. Como a demanda por periódicos e demais impressos era contínua e crescente, as oficinas da CPAD se encaminhavam para um inevitável colapso (O QUE..., 1963, p. 19).

Decorridos oito anos da aprovação da "Campanha pró-construção" do novo prédio da editora, a revista $A$ Seara publicou um convite com a seguinte mensagem: "A Casa Publicadora das Assembléias de Deus convida os Pastôres e as Igrejas em todo o Brasil para a solenidade de inauguração de sua nova sede, no dia 27 de setembro de 1970.” ([CONVITE], 1970, p. 1). A edição de novembro/dezembro de 1970 da mesma A Seara cuidou de apresentar em detalhes a solenidade de inauguração, ocorrida em setembro, e trouxe como ilustração de capa a imagem da fachada do novo edifício da CPAD (Figura 4), que, deve-se ressaltar, era bem diferente do que previa o projeto original, divulgado nessa mesma revista em novembro de 1963.

Figura 4 - Fotografia do novo prédio da CPAD.

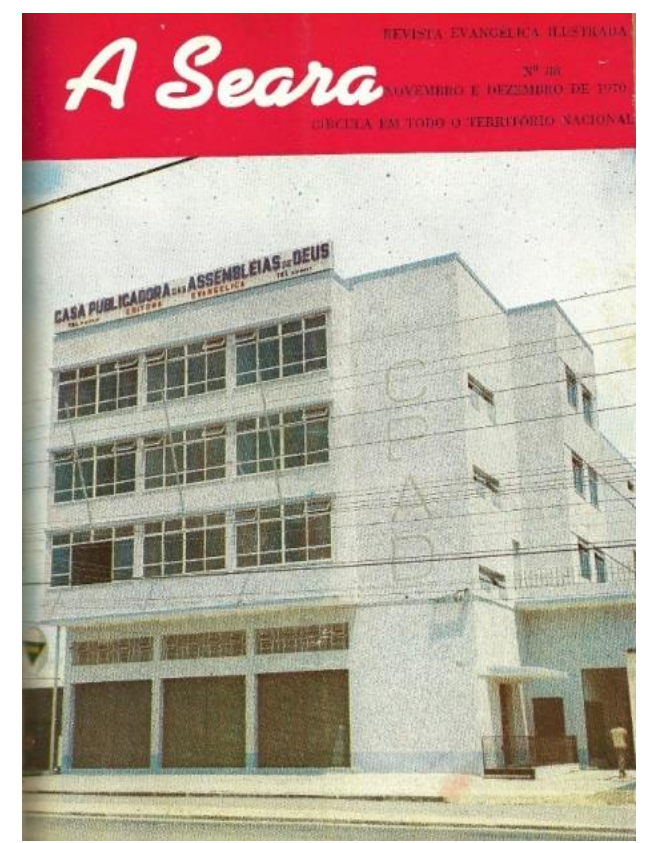

Fonte: A Seara, Rio de Janeiro, n. 88, p. 1, nov./dez. 1970. 
Ainda que fosse visível a discrepância entre o projeto esboçado na edição de novembro de 1963 de A Seara e o novo prédio, a solenidade de inauguração da nova sede da CPAD, que contou com a presença de 1.500 convidados, foi conduzida em clima de festa, pois as instalações representavam um inominável avanço diante do que antes se tinha à disposição. Essa diferença estava inscrita na reportagem que fez questão de contrapor o "majestoso edifício de linhas modernas" ao "velho casarão":

Belo edifício de quatro andares sendo um térreo e três superiores, com sua entrada artisticamente trabalhada em mármore, ferro, vidro e cerâmica, deixa ver no lado superior direito, uma bela placa retangular de bronze, em posição vertical na qual se lê o famoso versículo bíblico "até aqui os ajudou o senhor" $[\ldots]$ o andar térreo do novo edifício tem à frente uma ampla loja moderna de exposição e venda [...] descortina-se então um suntuoso e vasto salão aguardando a nova maquinaria que proporcionará grande salto para a idade técnica [...]. (DEUS..., 1970, p. 20)

A inauguração da nova sede da CPAD se deu em um momento extremamente favorável à modernização das oficinas gráficas do país. Alzira Alves de Abreu lembra que o contexto de crescimento econômico no Brasil, entre 1967 e 1973, impulsionado pela verticalização da indústria e pelo aumento da produção de bens duráveis, além da facilitação dos financiamentos pelo governo militar, que objetivava modernizar os meios de comunicação do país, teve reflexos diretos na estruturação da imprensa brasileira (ABREU, 2002, p. 20-21).

Foi nesse contexto, em 1972, que o "suntuoso" e "vasto" salão de máquinas, citado na matéria de A Seara de novembro/dezembro de 1970, recebeu novos equipamentos, entre eles uma aquisição que foi um marco na história da CPAD, sobretudo por permitir maior mobilidade na produção dos periódicos e melhoria na qualidade gráfica: a impressora rotativa Goss, de quatro módulos. A compra dessa máquina foi festejada pela editora, pois, com a importação de um equipamento desse porte, concretizava-se uma aspiração alimentada pela direção da CPAD desde a década de 1950. Com a Goss, foi substituído o sistema de composição a chumbo (linotipo) por um modelo de impressão muito mais eficaz: a impressão offset.

Com a chegada da Goss, as "grandes" e "pesadas" máquinas de linotipo foram substituídas por duas "máquinas de escrever elétricas" e uma "máquina de fotocomposição", que, de acordo com Huberth Hubertsson - técnico suíço que por um ano prestou assistência técnica à editora - eram equipamentos de fácil manuseio e operação. Entusiasmado, concluiu a matéria com a seguinte declaração: 
É importante ressaltar que a nova máquina atende as necessidades do momento e estará capacitada atender a grande expansão da Obra Pentecostal aqui no Brasil que certamente se dará dentro em breve. E no caso não haverá ônus extras, senão apenas alguma adição de despesas de papel e tinta $[\ldots]$ é provavelmente a primeira Igreja no mundo que consegue equipar uma gráfica de alto nível, com fotocomposição [...]. (GOSS..., 1972, p. 7-8).

O novo prédio e o maquinário moderno foram elementos decisivos para que a CPAD se firmasse entre as grandes editoras do gênero no Brasil e na América Latina. Não que posteriormente ela não viesse a enfrentar dificuldades, mas, na sede da Estrada Vicente de Carvalho, na cidade do Rio de Janeiro, onde ficou 22 anos, a CPAD encontrou a base necessária para o vertiginoso crescimento experimentado nas décadas de 1970 e 1980, a despeito de todas as dificuldades econômicas enfrentadas pelo país entre os anos finais do regime militar e o início do processo de redemocratização.

\section{Considerações finais}

A CPAD, nascida da iniciativa frugal dos fundadores, que queriam fazer circular um modesto jornal que representasse a instituição, por uma complexa mescla de voluntarismo e pressões contingenciais, cresceu e ganhou centralidade na estrutura da AD, tornando-se um órgão de sustentação financeira da própria CGADB. A percepção de que a produção em larga escala de impressos, quando feita por uma editora bem-estruturada, poderia gerar vultosos lucros colocou a CPAD no centro das atenções. Estar à frente da editora em tempos de penúria era um sacerdócio, mas tê-la nas mãos como empreendimento empresarial consolidado de renda certa e crescente era outra coisa. Como destacou o sociólogo Paul Freston, a editora se tornou a principal fonte de recursos financeiros da Convenção Geral das ADs, ou, no dizer de um ex-editor entrevistado por Freston (1994, p. 92), "um cavalo de sela muito bem equipado que todo mundo quer sentar em cima".

De todo modo, ato pioneiro, a criação da CPAD representa um marco decisivo no estabelecimento da imprensa pentecostal no Brasil. Seus jornais, revistas e demais impressos irrigaram o mercado editorial brasileiro com um número incalculável de materiais, com invejável inserção no território brasileiro e também em alguns países da América Latina. Às ciências sociais, esse grande número de impressos presta uma relevante contribuição no estudo dessa centenária instituição que é a $\mathrm{AD}$ e ao próprio movimento pentecostal. Por fim, vale ressaltar o cuidado institucional da própria CPAD 
com a guarda, a conservação e a catalogação de seu vasto acervo de periódicos por meio do Centro de Estudos do Movimento Pentecostal (Cemp). Criado em setembro de 2009, o Cemp detém um riquíssimo acervo histórico, com destaque para a hemeroteca, em que se encontram milhares de páginas de periódicos editados pela CPAD.

\section{Referências}

ABREU, Alzira Alves de. A modernização da imprensa (1970-2000). Rio de Janeiro: Jorge Zahar, 2002.

ALMEIDA, Abraão de. História das Assembléias de Deus no Brasil. Rio de Janeiro: CPAD, 1982.

ARAUJO, Isael de. Dicionário do movimento pentecostal. Rio de Janeiro: CPAD, 2007.

A SEARA, Rio de Janeiro, n. 35, p. 1 nov./dez. 1963.

A SEARA, Rio de Janeiro, n. 88, p. 1, nov./dez. 1970.

BELOCH, Israel; ABREU, Alzira Alves de et al. Dicionário histórico-biográfico brasileiro pós-1930. Rio de Janeiro: FGV/CPDOC, 2001.

BRASIL. Decreto no 5.977, de 10 de novembro de 1943. Altera a tabela do salário mínimo, e dá outras providências. Disponível em: https://www2.camara.leg.br/legin/fed/declei/1940-1949/decreto-lei-5977-10-novembro1943-416056-publicacaooriginal-1-pe.html. Acesso em: 14 maio 2019.

BRASIL. Decreto no 30.342, de 24 de dezembro de 1951. Altera as tabelas do salário mínimo dá outras previdências. Disponível em: https://www2.camara.leg.br/legin/fed/decret/1950-1959/decreto-30342-24-dezembro1951-340732-publicacaooriginal-1-pe.html. Acesso em: 14 maio 2019.

BRASIL. Decreto no 39.604-A, de 14 de julho de 1956. Altera a tabela de salário mínimo e dá outras providências. Disponível em: https://www2.camara.leg.br/legin/fed/decret/19501959/decreto-39604-a-14-julho-1956-519762-publicacaooriginal-1-pe.html. Acesso em: 14 maio 2019.

BRASIL. Decreto no 45.106-A, de 24 de dezembro de 1958. Altera a tabela de saláriomínimo e dá outras providências. Disponível em: https://www2.camara.leg.br/legin/fed/decret/1950-1959/decreto-45106-a-24-dezembro1958-384179-publicacaooriginal-1-pe.html. Acesso em: 14 maio 2019. 
BREVE histórico da Casa Publicadora. Mensageiro da Paz. Rio de Janeiro, ano 40, n. 22 , p. 11 , nov. 1970 .

CAMARGO, Mario. Gráfica, arte e indústria no Brasil: 180 anos de história. 2. ed. São Paulo: Bandeirantes Gráfica; Edusc, 2003.

CAMPANHA pró-construção da Casa Publicadora. A Seara, Rio de Janeiro, n. 30, p. 12, jan./fev. 1963.

[CONVITE]. A Seara, Rio de Janeiro, n. 86, p. 1, jul./ago. 1970.

CPAD: 50 anos evangelizando pela imprensa. Mensageiro da Paz, Rio de Janeiro, ano LX, n. 1238 , p. $14-15$, mar. 1990.

CPAD. Extratos de Estatuto. Diário Oficial da União: Seção 1, Brasília, DF, p. 2039, 14 fev. 1947.

CPAD. História da Convenção Geral das Assembléias de Deus no Brasil. Rio de Janeiro, 2004.

DEUS converte um sonho pioneiro em gloriosa realidade. A Seara, Rio de Janeiro, n. 88, p. 20, nov./dez. 1970.

EDITORIAL. A Seara. Rio de Janeiro, n. 87, p. 02, set./out. 1970.

ELEUTÉRIO, Maria de Lourdes. Imprensa a serviço do progresso. In: LUCA, Tania Regina de; MARTINS, Ana Luiza (org.). História da imprensa no Brasil. São Paulo: Contexto, 2008. p. 83-102.

EIS a Casa Publicadora do Futuro! A Seara, Rio de Janeiro, n. 35, p. 1, nov./dez. 1963.

ENTREVISTA com João Pereira de Andrade e Silva. A Seara. Rio de Janeiro, n. 87, p. 19, set./out. 1970.

FRESTON, Paul. Breve história do pentecostalismo brasileiro. In: ANTONIAZZI, Alberto. Nem anjos nem demônios: uma interpretação sociológica do pentecostalismo. Rio de Janeiro: Vozes, 1994. p. 67-159.

GOSS - renovação oportuna. Mensageiro da Paz, Rio de Janeiro, ano 42, n. 6, p. 7-8, mar. 1972.

LUCA, Tania Regina de. História dos, nos e por meio dos periódicos. In: PINSKY, Carla 
Bassanezi (org.). Fontes Históricas. São Paulo: Contexto, 2006. p. 111-153.

OLIVEIRA, Joanyr. As Assembléias de Deus no Brasil: sumário histórico ilustrado. Rio de Janeiro: CPAD, 1997.

O QUE é a Casa Publicadora... A Seara, Rio de Janeiro, n. 35, p. 5, nov./dez. 1963.

POR QUE construir a nova casa? Discurso de Deolando Almeida na CGADB de 1962. A Seara, Rio de Janeiro, n. 35, p. 8, nov./dez. 1963.

RIO DE JANEIRO (RJ). 3 o Ofício de Registro de Títulos e Documentos do Rio de Janeiro, livro K, n. 01, 1947.

ROLIM, Francisco Cartaxo. Pentecostalismo: Brasil e América Latina. Petrópolis: Vozes, 1994.

ROLIM, Francisco Cartaxo. O que é pentecostalismo?. São Paulo: Brasiliense, 1987.

SOUZA, Beatriz Muniz de. A experiência da salvação: pentecostais em São Paulo. São Paulo: Duas Cidades, 1969.

Submetido em: 29.09.2018

Aprovado em: 05.06.2019 